J. Electroanal. Chem., 220 (1987) 83-100

Elsevier Sequoia S.A., Lausanne - Printed in The Netherlands

\title{
A MODEL FOR ANODIC HYDROUS OXIDE GROWTH AT IRIDIUM
}

PETER G. PICKUP and V.I. BIRSS

Department of Chemistry, University of Calgary, Calgary, Alberta, T2N 1 N4 (Canada)

(Received 2nd April 1986)

ABSTRACT

A detailed investigation of the electrochemistry of $\mathrm{Ir}$ in $0.5 \mathrm{M} \mathrm{H}_{2} \mathrm{SO}_{4}$ has been used as an experimental basis for a model for oxide growth at Ir. It appears that a compact oxide (probably $\mathrm{IrO}_{2}$ ) is formed initially. At potentials above $+1.2 \mathrm{~V}$ vs. RHE, the outer monolayer of this compact oxide is oxidised and becomes hydrated. The hydrated surface layer inhibits further oxidation of the compact oxide and therefore only one monolayer of hydrous oxide can be formed at constant potential. To obtain more hydrous oxide than this, the compact oxide must be continually reduced to Ir metal and reformed, by cycling of the potential. On each cycle, the hydrated surface layer of the compact oxide remains after reduction of the compact oxide. Thus, this material accumulates as a hydrous oxide layer.

\section{INTRODUCTION}

Although there have been many studies of anodic hydrous oxide growth at Ir, the mechanism of this process has still not been elucidated [1-14]. An understanding of the mechanism of oxide growth at Ir is important in gaining a better understanding of the structure and electrochemical properties of the hydrous oxide. Further, if it is known how the hydrous oxide is formed, then it should be possible to choose the growth conditions to optimise either the growth rate or the properties of the oxide.

Following a number of investigations of anodic oxide formation on $\operatorname{Ir}[15-20]$, it was realised [21-25] that thick layers of an electroactive, electrochromic, conducting oxide could be built up on the electrode by potential cycling. Virtually all the iridium atoms in this oxide can be cycled reversibly between $\operatorname{Ir}(\mathrm{III})$ and $\operatorname{Ir}(\mathrm{IV})$ at a formal potential $\left(E^{\circ \prime}\right)$ of $+0.97 \mathrm{~V}$ vs. RHE in $1 \mathrm{M} \mathrm{H}_{2} \mathrm{SO}_{4}$ [22]. It is now accepted that this is a hydrated form of iridium oxide. It has been suggested recently that this hydrous oxide should be regarded as a gel-like material containing chains of oxygen bridged hydroxy-aquo complexes of Ir [11].

It has been found that hydrous oxide growth on Ir occurs only under potential cycling (cyclic scans or pulses) conditions and will not occur at any fixed potential $[2,8,23]$. For sustained hydrous oxide growth to occur, the potential must exceed

0022-0728/87/\$03.50 (C) 1987 Elsevier Sequoia S.A 
critical upper and lower potential limits during each cycle. These critical limits depend somewhat on the electrolyte and the growth conditions (scanning or pulsing, cycle time). In $0.5 \mathrm{M} \mathrm{H}_{2} \mathrm{SO}_{4}$, they are ca. +1.15 and $+0.30 \mathrm{~V}$ vs. RHE, respectively $[2,23]$. Several authors have proposed explanations for this phenomenom.

Mozota and Conway [8] suggested that Ir oxide formed in the positive sweep is incompletely reduced in the negative sweep and accumulates in a hydrated form. However, no explanation was given for why the oxide remaining after the negative sweep becomes hydrated.

Burke and co-workers $[12,14]$ have invoked a comparison of Ir oxide growth with oxide growth at $\mathrm{Au}[26,27]$ and $\mathrm{Pt}[28,29]$. At these metals, two forms of oxide have been identified. First, a thin compact oxide is formed and then, at higher positive potentials ( $>2.0 \mathrm{~V}$ vs. RHE), the outer layers of this oxide become hydrated and more dispersed. This process will continue at constant potentials above $2.0 \mathrm{~V}$ vs. RHE. The compact inner layer remains at an almost constant thickness while the outer hydrous layer grows to some limiting thickness. However, the rate of hydrous oxide growth can be enhanced by reducing periodically the inner compact oxide layer, which is more easily reduced to the metal than is the hydrous layer. Supposedly, a newly formed inner layer is more readily hydrated than is an aged layer.

In the case of Ir, however, hydrous oxide growth does not occur under constant potential conditions. Perhaps this is because a sufficiently high potential cannot be used as any hydrous oxide formed above $+1.6 \mathrm{~V}$ is dissolved immediately [3,23].

By comparison with hydrous oxide growth at $\mathrm{Pt}$, Burke and Scannell [14] concluded that for hydrous oxide growth to occur at Ir, an initially formed compact anhydrous oxide layer must be reduced substantially and then reoxidised. This reoxidation of "displaced" metal atoms leads to a dispersed hydrated oxide.

Although this mechanism is feasible, it is not clear why the displaced metal atoms should form a different type of oxide. However, an important feature of the work of Burke and co-workers is the concept that a compact anhydrous oxide is formed initially and that this inhibits the growth of the hydrous oxide in some way.

In this paper, we present the results of a detailed electrochemical investigation of oxide growth at $\mathrm{Ir}$ in $0.5 \mathrm{M} \mathrm{H}_{2} \mathrm{SO}_{4}$. The results are then used as a basis for a model of oxide growth which encompasses both Conway's [8] and Burke's [12,14] mechanisms.

EXPERIMENTAL

General

A three-compartment glass cell was used in all of this work. The working electrode was $99.9 \%$ purity Ir wire (Johnson Matthey; $0.5 \mathrm{~mm}$ dia.). The length in contact with the electrolyte was determined by the position of a polyethylene collar which was replaced between most sets of experiments. To attach a collar, a small length (ca. $1 \mathrm{~mm}$ ) of polyethylene tubing was slid onto the wire to the required 
distance (typically ca. $6 \mathrm{~mm}$ ) and then heated lightly with a flame, causing it to melt slightly and form a water-tight collar. In this paper, geometric electrode areas are represented by " $\mathrm{cm}^{2}$ " and real electrode areas by "real $\mathrm{cm}^{2}$ ".

The reference electrode was a hydrogen electrode in the same solution as that in the main compartment of the cell (RHE) and all potentials are quoted relative to this. It was separated from the working electrode by a Luggin probe. The counter electrode was a large-area Pt gauze in a compartment separated by a glass frit from the working-electrode compartment.

An EG \& G PARC 173 potentiostat was used with a PARC 175 Universal Programmer and a PARC 179 digital coulometer. Voltammograms were recorded on a Hewlett-Packard 7044A X-Y recorder.

Reagent ACS grade sulphuric acid (Fisher) and triply distilled water were used throughout this work.

\section{Electrode pretreatment}

As with $\mathrm{Pt}$, it is important to achieve a reproducible Ir surface when studying the first few monolayers of oxide growth. The reproducibility is most conveniently assessed by examining the hydrogen adsorption/desorption region of a voltammogram obtained in $0.5 \mathrm{M} \mathrm{H}_{2} \mathrm{SO}_{4}$ [30].

The surface pretreatment procedure used in this work was devised, not only to produce a reproducible surface, but also to remove any oxide that had been formed in a previous experiment. In this way, the same wire electrode could be used for many experiments without exposure to any chemicals other than aqueous $\mathrm{H}_{2} \mathrm{SO}_{4}$ and without any mechanical cleaning.

The pretreatment procedure is as follows. The electrode is potentiostated at $2 \mathrm{~V}$ vs. RHE for $5 \min$ in $2 \mathrm{M} \mathrm{H}_{2} \mathrm{SO}_{4}$, which is continually degassed and stirred by $\mathrm{N}_{2}$. After a further $5 \mathrm{~min}$ at $0 \mathrm{~V}$ under these conditions, the potential is cycled between 0 and $+1.8 \mathrm{~V}$ at $100 \mathrm{mV} / \mathrm{s}$ for $5 \mathrm{~min}$. The upper limit is reduced to $+1.2 \mathrm{~V}$ for a further $15 \mathrm{~min}$ of cycling and then the electrode is transferred to the electrolyte to be used for the experiment $\left(0.5 \mathrm{M} \mathrm{H}_{2} \mathrm{SO}_{4}\right.$ in this work) and cycled between the same limits for $30 \mathrm{~min}$. This leads to a reproducible, although not totally oxide-free surface (see below).

In a variation of this procedure, the holding of the potential at $0 \mathrm{~V}$ in the $2 M$ acid solution was omitted and the cycling between 0 and $+1.2 \mathrm{~V}$ was carried out for only $5 \mathrm{~min}$ in each solution. Results following this procedure were not significantly different from those following the longer pretreatment, except that there was slightly more residual hydrous oxide following the shortened procedure (see below).

To test the reproducibility of these surface pretreatment procedures, the hydrogen adsorption and desorption charges $\left(q_{\mathrm{H}}\right)$ were measured routinely. A voltammogram recorded between +0.03 and $+0.40 \mathrm{~V}$ at $100 \mathrm{mV} / \mathrm{s}$ was integrated between +0.06 and $+0.40 \mathrm{~V}$ (Fig. 1A) and then the calculated double-layer charge was subtracted from this. As the anodic and cathodic charges were equivalent, within experimental error, an average $\left(q_{\mathrm{H}}\right)$ is used. It is possible to measure the double-layer 


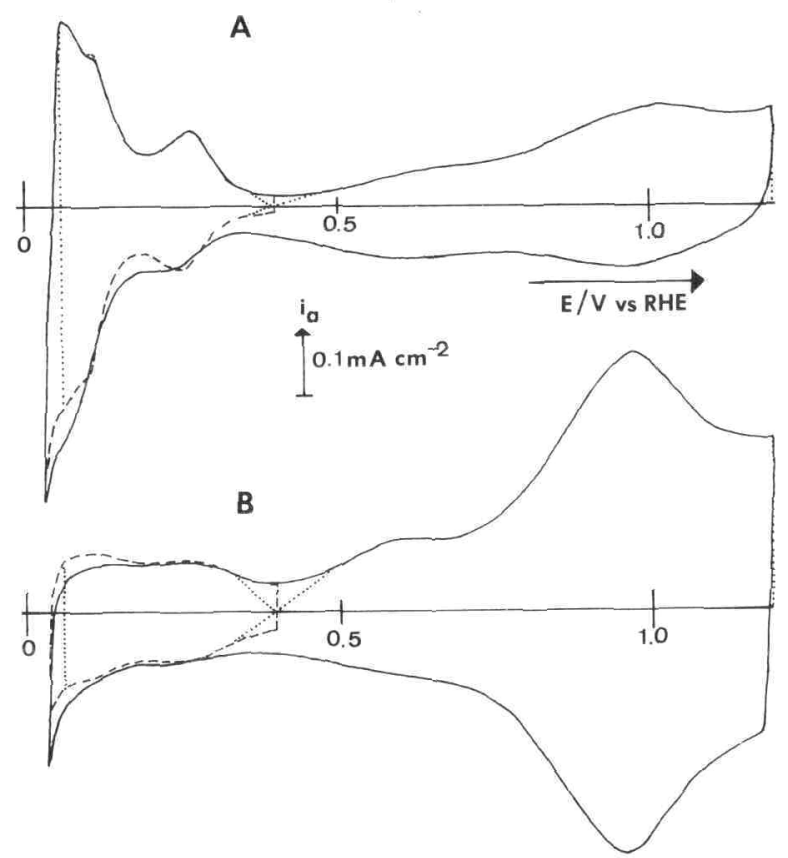

Fig. 1. Cyclic voltammograms at $100 \mathrm{mV} / \mathrm{s}$ of $\mathrm{Ir}$ in $0.5 \mathrm{M} \mathrm{H}_{2} \mathrm{SO}_{4}$. (A) Bare $\mathrm{Ir}$, (B) after hydrous oxide growth for 400 cycles between +0.15 and $+1.50 \mathrm{~V}$ at $1 \mathrm{~V} / \mathrm{s}$. (The upper potential limit was $1.2 \mathrm{~V}$ $(-)$ or $0.4 \mathrm{~V}(-\ldots)$.) The dotted lines indicate the boundaries used during integration.

capacitance $\left(C_{\mathrm{dl}}\right)$ at potentials between ca. +0.35 and $+0.45 \mathrm{~V}$, since these potentials are too high for $\mathrm{H}$ adsorption and too low for $\mathrm{OH}$ adsorption. Using a scan speed of $10 \mathrm{~V} / \mathrm{s}$, an average result of $C_{\mathrm{dl}}=25 \mu \mathrm{F} / \mathrm{real} \mathrm{cm} \mathrm{cm}^{2}$ was obtained. This is in fair agreement with the value of $31 \mu \mathrm{F} / \mathrm{real} \mathrm{cm}^{2}$ obtained by Hoare [17].

An interesting result arose from the routinely determined values of $q_{\mathrm{H}}$. The new piece of Ir wire initially had a roughness factor $\left(\mathrm{rf}\right.$ determined from $q_{\mathrm{H}} /(0.65 \times 0.218$

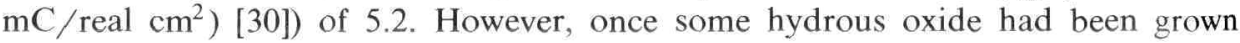
during experimentation and then removed by the above procedure, the roughness factor had decreased. This decrease in the rf was observed for the next two oxide growth and removal cycles and then the rf reached a constant value of 2.4. The charge under the monolayer oxide region of the voltammogram $(0.40$ to $1.20 \mathrm{~V})$ decreased in proportion to the decrease in $q_{\mathbf{H}}$, indicating that the rf really had decreased. Thus it appears that oxide growth and removal can cause an electropolishing of Ir electrodes and eventually leads to a reproducible rf. For all results presented here, the roughness factor was $2.4 \pm 0.2$.

Determination of the quantity of hydrous oxide

The charge under the oxide region $(+0.40 \mathrm{~V}$ to the oxygen evolution region at ca. $+1.5 \mathrm{~V}$; Fig. 1B) of a cyclic voltammogram of an electrode coated with hydrous 
oxide gives a direct measure of the amount of hydrous oxide present [3]. However, some decisions must be made regarding the upper potential limit to be used for the integration and how the charges due to the double layer and compact inner oxide are accounted for.

In this work, we have used either +1.20 or $+1.30 \mathrm{~V}$ as the upper potential limit for the integration. The total anodic charge density between $+0.4 \mathrm{~V}$ and one of these limits, minus the calculated double-layer charge for bare Ir metal (see above), can be used as a relative measure of the quantity of hydrous oxide $\left(q_{\mathrm{ox}, 1.2}\right.$ and $q_{\mathrm{ox} .1 .3}$, respectively; $\left.q_{\mathrm{ox}, 1.2} \sim 0.8 q_{\mathrm{ox}, 1.3}\right)$. In this work, we have been concerned mainly with changes in the quantity of hydrous oxide which occur during a particular period of oxide growth. Thus, $\Delta q_{\mathrm{ox}, 1.3}$ is the relevant parameter, and is simply the difference in $q_{\mathrm{ox}, 1.3}$ before and after any specified oxide growth period.

To compare $q_{\mathrm{ox}, 1.3}$ values with the charge enhancement factor (CEF) parameter used by Mozota and Conway [8,31], or the charge capacity used by Burke and co-workers [11,22], conversion factors of $1.2\left(\mathrm{~cm}^{2} / \mathrm{mC}\right)$ and 1.3 respectively, should be used.

\section{RESULTS AND DISCUSSION}

\section{The effect of hydrous oxide growth on hydrogen adsorption on Ir}

At potentials below $+0.40 \mathrm{~V}$, hydrogen atoms adsorb reversibly onto $\mathrm{Ir}, 0.65$ of a monolayer being formed at $+0.06 \mathrm{~V}$ [30]. On polycrystalline $\mathrm{Ir}$ in $0.5 \mathrm{M} \mathrm{H}_{2} \mathrm{SO}_{4}$, there are three (Fig. 1A) or sometimes four [8] waves in the voltammogram corresponding to this process. The magnitude of these waves is very dependent upon the condition of the Ir surface and can therefore be used to probe changes in the surface.

One of the unique features of Ir is that the hydrogen adsorption and desorption waves do not disappear completely when numerous layers of hydrous oxide are grown [20-24]. This has led to the view that the hydrous oxide is a very porous solid or gel which lies on top of the Ir substrate, but is not strongly bound to it, and allows free access of electrolyte to it [8].

Figure $1 \mathrm{~A}$ shows a cyclic voltammogram of a clean Ir electrode in $0.5 \mathrm{M} \mathrm{H}_{2} \mathrm{SO}_{4}$. The charge under the hydrogen adsorption/desorption region was measured as described above. Here, $q_{\mathrm{H}}$ is $0.35 \mathrm{mC} / \mathrm{cm}^{2}$, which gives a roughness factor of 2.5 .

Figure $1 \mathrm{~B}$ shows a voltammogram of the same electrode after hydrous oxide growth. The oxide was grown by cycling the potential at $1 \mathrm{~V} / \mathrm{s}$ between +0.15 and $+1.50 \mathrm{~V}$ for 400 cycles. The reversible hydrous oxide $\operatorname{Ir}(\mathrm{III}) \leftrightarrow \operatorname{Ir}(\mathrm{IV})$ wave has developed at $E^{\circ \prime}=+0.963 \mathrm{~V}$ while the hydrogen adsorption and desorption waves have virtually disappeared. This indicates that the underlying Ir metal is no longer fully exposed to the electrolyte. It is now difficult to estimate $q_{\mathrm{H}}$ because it appears that the double-layer capacitance has increased considerably, as judged by the magnitude of the current change on sweep reversal at $+0.40 \mathrm{~V}$ and the almost featureless current-potential profile in the $\mathrm{H}$ region. A similar apparent increase in 


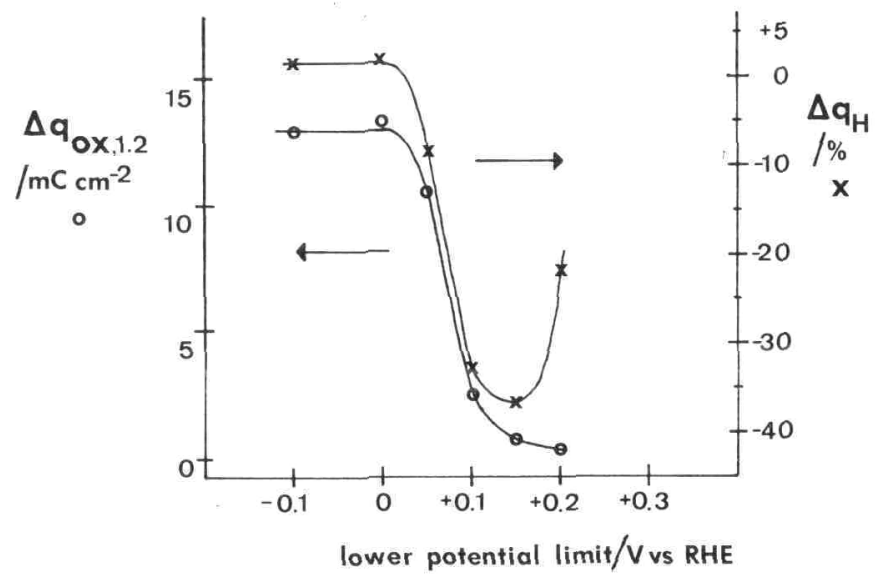

Fig. 2. Amount of oxide growth $\left(\Delta q_{\mathrm{ox}, 1.2}\right)$ and change in $q_{\mathrm{H}}\left(\Delta q_{\mathrm{H}} \%\right)$ vs. lower potential limit for 400 cycles at $1 \mathrm{~V} / \mathrm{s}$ with an upper potential limit of $+1.5 \mathrm{~V}$.

$C_{\mathrm{dl}}$, following oxide growth at Ir, was observed by Hoare [17]. If $q_{\mathrm{H}}$ is estimated in the usual way (obviously an underestimation), a $37 \%$ decrease is found, as compared with the bare electrode.

The above experiment was repeated at various lower potential limits for the 400 cycles of oxide growth, while maintaining the upper limit at $+1.50 \mathrm{~V}$ and the scan speed at $1 \mathrm{~V} / \mathrm{s}$. Figure 2 shows plots of the percentage change in $q_{\mathrm{H}}$ and of the quantity of oxide growth, as functions of the lower potential limit. It can be seen that there is an excellent correlation between the decrease in the rate of oxide growth and the decrease in $q_{\mathrm{H}}$ as the lower limit is made more positive. Burke and co-workers [22] and Gottesfeld and McIntyre [2] have published similar results for the effect of the lower limit on the rate of oxide growth.

When the lower limit is less than or equal to $0 \mathrm{~V}$, maximum oxide growth per cycle occurs and $q_{\mathrm{H}}$ is not affected by oxide growth. In these cases, the oxide can be regarded as a hydrous gel which is not strongly bound to the underlying Ir metal. Thus, its presence does not affect the electrochemical properties of the metal surface.

However, when the lower limit is more positive than $0 \mathrm{~V}$, the hydrous oxide growth rate is decreased and $q_{\mathrm{H}}$ decreases during oxide growth. This implies that, under these conditions, some material is accumulating on the Ir metal surface, blocking the $\mathrm{H}$-adsorption sites and inhibiting hydrous oxide growth. This is probably some form of oxide other than the hydrous oxide. It is presumably reduced to Ir metal at ca. $0 \mathrm{~V}$ and so it does not accumulate if the lower potential limit is $0 \mathrm{~V}$ or less. This must be the compact anhydrous oxide discussed by Burke and co-workers $[12,14]$. However, since the identity of this oxide is unknown, we will refer to it merely as the "inner oxide". 
The $\Delta q_{\mathrm{H}} \%$ result for a lower potential limit of $+0.20 \mathrm{~V}$ in Fig. 2 appears to be anomalous, but is correct since this point was obtained repeatedly. This apparent anomaly arose because in this case, the $\mathrm{H}$-region waves grew back rapidly when the potential was cycled to $0.03 \mathrm{~V}$. Thus, by the time a voltammogram was recorded, much of the inner oxide had been reduced. This was not a problem when less positive lower potential limits were used as in these cases, the inner oxide was much more stable to reduction. The potential could be cycled through the $\mathrm{H}$ waves many times with little increase in the size of these waves.

Several other workers have observed $20-30 \%$ decreases in $q_{\mathrm{H}}$ following hydrous oxide growth at $\operatorname{Ir}[8,20,21,24]$. The present results indicate that in these cases, the lower limit must have been insufficiently low to cause complete reduction of the inner oxide. Even with the lower limit below $0 \mathrm{~V}$, it is still possible for an accumulation of the inner oxide to occur if the scan rate is high or the pulse time is short and the hydrous oxide is thick. Under these circumstances, the $i R$ drop in the solution and the film can make the effective lower potential limit significantly more positive than the limit set.

\section{The inner oxide}

The $q_{\mathrm{H}}$ results presented in the previous section support Burke's postulate [12,14] of a "compact anhydrous" oxide at Ir between the hydrous oxide layer and the metal surface. The growth and reduction of this inner oxide are examined here.

Figure 3 shows consecutive positive and negative linear sweep voltammograms of a bare Ir electrode in $0.5 \mathrm{M} \mathrm{H}_{2} \mathrm{SO}_{4}$. The total charge passed during the sweep from +0.20 to $+1.20 \mathrm{~V}$ and a subsequent 5 min holding of the potential at $+1.20 \mathrm{~V}$ was measured. This was also done for the negative sweep with a 5 min hold at $+0.20 \mathrm{~V}$. This sequence of sweeping and then holding the potential was repeated ten times and the measured charge densities are shown in Table 1.

After the first few cycles, constant values of 1.1 and $1.0 \mathrm{mC} / \mathrm{real} \mathrm{cm}^{2}$ were established for $q_{\mathrm{an}}$ and $q_{\mathrm{cath}}$, respectively. These charges correspond to ca. 5 electrons per surface Ir atom. However, there was no development of the reversible wave at ca. $+1 \mathrm{~V}$, indicating that no hydrous oxide was formed during these ten

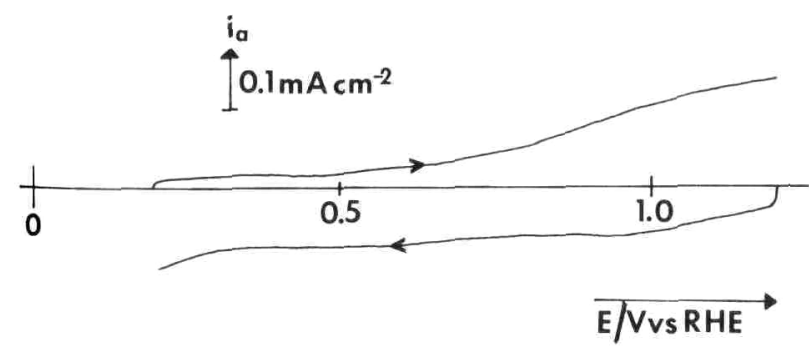

Fig. 3. Positive and negative linear sweep voltammograms at $100 \mathrm{mV} / \mathrm{s}$ of $\mathrm{Ir}$ in $0.5 \mathrm{M} \mathrm{H}_{2} \mathrm{SO}_{4}$. 
TABLE 1

Charge densities passed during consecutive scans at $100 \mathrm{mV} / \mathrm{s}$ between 0 and $+1.20 \mathrm{~V}$ with holding of the potential at each limit for $5 \mathrm{~min}$

\begin{tabular}{lll}
\hline $\begin{array}{l}\text { Cycle } \\
\text { number }\end{array}$ & $\begin{array}{l}\text { Anodic charge density } \\
\left.q_{\text {an }} / \mathrm{mC}_{(\text {real cm }}{ }^{-2}\right)\end{array}$ & $\begin{array}{l}\text { Cathodic charge density } \\
\left.q_{\text {cath }} / \mathrm{mC}_{(\mathrm{real} \mathrm{cm}}{ }^{-2}\right)\end{array}$ \\
\hline 1 & 1.16 & 0.94 \\
2 & 1.12 & - \\
3 & 1.10 & 0.97 \\
4 & 1.08 & 0.99 \\
5 & 1.08 & 0.99 \\
6 & 1.08 & 0.99 \\
7 & 1.08 & 1.00 \\
8 & 1.08 & 0.99 \\
9 & 1.08 & 0.99 \\
10 & 1.08 & 0.99 \\
\hline
\end{tabular}

cycles. Thus, one must conclude that several layers of some other form of oxide (the inner oxide) were produced and reduced back to the metal during each of these cycles. This inner oxide growth is presumably similar to oxide growth at $\mathrm{Pt}$ [32-36] and probably occurs by a place-exchange mechanism [32]. A difference from the behaviour of $\mathrm{Pt}$ is that no well-defined reduction peak can be obtained for the inner oxide at Ir. At Ir, the inner oxide is slowly reduced at potentials below $+0.40 \mathrm{~V}$. This has been discussed by Mozota and Conway [8].

The slight difference between the anodic and cathodic charges in Table 1 is probably due to oxidation of impurities in the electrolyte. Oxidation of impurities adsorbed on the electrode would explain the initial larger difference between the anodic and cathodic charges.

Hydrous oxide growth

Further experiments similar to that described above were performed in order to determine what conditions promote hydrous oxide growth. These experiments will be described in a shorthand notation in which the above experiment for inner oxide growth is written as;

$+0.20(300 \mathrm{~s}) \underset{100 \mathrm{mV} / \mathrm{s}}{\stackrel{100 \mathrm{mV} / \mathrm{s}}{10}}+1.20(300 \mathrm{~s}) ; 10$ cycles

Table 2 shows the results of these experiments, giving the amount of hydrous oxide growth per cycle (measured as $\Delta q_{\mathrm{ox}, 1.3}$ ) for various experiments which have been decribed with the above notation.

Experiment 1 is the benchmark experiment and represents the most efficient (in terms of number of cycles) method of growing the hydrous oxide. During repetitions of experiment 1 , it became obvious that the growth per cycle decreased linearly with the amount of hydrous oxide already on the electrode. A least-squares fit of the 
TABLE 2

Hydrous oxide growth $\left(q_{\mathrm{ox}, 1.3}\right)$ per cycle during various cycling procedures

\begin{tabular}{|c|c|c|c|}
\hline $\begin{array}{l}\text { Exp. } \\
\text { no. }\end{array}$ & Cycling procedure $^{a}$ & $\begin{array}{l}\text { Number } \\
\text { of cycles }\end{array}$ & $\begin{array}{l}\text { Oxide growth per cycle } \\
/ \mathrm{mC}\left(\text { real } \mathrm{cm}^{-2} \text { ) }\right.\end{array}$ \\
\hline $1^{c}$ & $0(100 \mathrm{~s}) \underset{\text { step }}{\stackrel{\text { step }}{\leftrightarrow}} 1.50(100 \mathrm{~s})$ & 5 & $\begin{array}{l}0.091,0.093,0.097 \\
0.102,0.106,0.110 \\
0.111, \text { Av. }=0.101\end{array}$ \\
\hline 2 & $0.20(300 \mathrm{~s}) \underset{100 \mathrm{mV} / \mathrm{s}}{\stackrel{100 \mathrm{mV} / \mathrm{s}}{\rightleftarrows}} 1.20(300 \mathrm{~s})$ & 10 & 0 \\
\hline & $\stackrel{100 \mathrm{mV} / \mathrm{s}}{\longrightarrow} 1.20(300 \mathrm{~s}) \stackrel{\text { step }}{\rightarrow}$ & & \\
\hline 3 & $0.20(300 \mathrm{~s}) \underset{100 \mathrm{mV} / \mathrm{s}}{\leftrightarrows} 1.20(120 \mathrm{~s}) \underset{\text { step }}{\leftarrow} 1.50(100 \mathrm{~s})$ & 5 & 0.019 \\
\hline & $\stackrel{\text { step }}{\rightarrow} 0.20(120 \mathrm{~s}) \stackrel{100 \mathrm{mV} / \mathrm{s}}{\longrightarrow} 1.20(300 \mathrm{~s}) \stackrel{\text { step }}{\rightarrow}$ & & \\
\hline 4 & 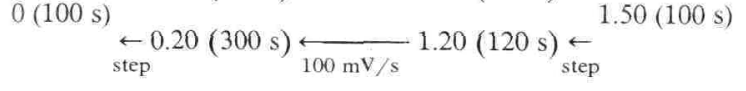 & 3 & 0.025 \\
\hline $5^{\mathrm{d}}$ & $0(100 \mathrm{~s}) \stackrel{100 \mathrm{mV} / \mathrm{s}}{\longleftrightarrow} 1.50(100 \mathrm{~s})$ & 2 & 0.043 \\
\hline & $100 \mathrm{mV} / \mathrm{s}$ & 5 & 0.086 \\
\hline & $\stackrel{\text { step }}{\longrightarrow} 1.20(1200 \mathrm{~s}) \stackrel{\text { step }}{\rightarrow}$ & & \\
\hline 6 & $0(100 \mathrm{~s}) \longleftarrow_{\text {step }} 1.50(100 \mathrm{~s})$ & 5 & 0.095 \\
\hline 7 & 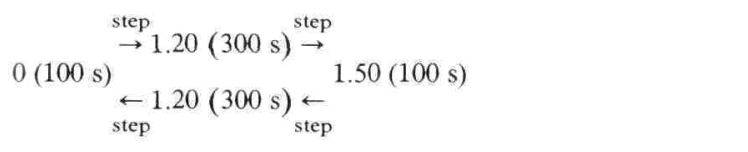 & 5 & 0.101 \\
\hline & step & & \\
\hline 8 & $0(100 \mathrm{~s}) \underset{\text { step }}{\leftarrow 0.40(300 \mathrm{~s}) \underset{\text { step }}{\leftarrow}} 1.50(100 \mathrm{~s})$ & 5 & 0.044 \\
\hline & step & & \\
\hline 9 & $0(100 \mathrm{~s}) \underset{\text { step }}{\leftarrow 0.40(1200 \mathrm{~s}) \underset{\text { step }}{\leftarrow}} 1.50(100 \mathrm{~s})$ & 3 & 0.057 \\
\hline
\end{tabular}

${ }^{a}$ See text for explanation of notation.

${ }^{b}$ Corrected for the quantity of hydrous oxide already present (see text).

${ }^{c}$ This experiment was performed 7 times.

d This experiment was performed twice. 
experiment $1 \Delta q_{\mathrm{ox}, 1.3}$ data vs. $q_{\mathrm{ox}, 1.3}$ (proportional to total hydrous oxide quantity or

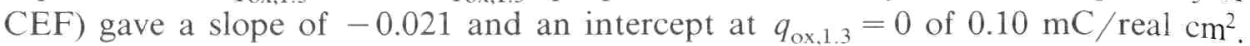
The origin of the decrease in growth rate with increasing $q_{\mathrm{ox}, 1.3}$ is probably slow dissolution of the hydrous oxide at $+1.50 \mathrm{~V}$. The rate of dissolution would be expected to be proportional to $q_{o x, 1.3}$.

Since many of the experiments in Table 2 were done consecutively without removal of the oxide grown in previous experiments, we have corrected for the presumed loss of hydrous oxide at $+1.5 \mathrm{~V}$ by extrapolation to zero $q_{\text {ox.1.3 }}$, using a slope of -0.021 . The highest $q_{\text {ox }, 1.3}$ involved was $2.3 \mathrm{mC} / \mathrm{real} \mathrm{cm}^{2}$.

Experiment 2 is the experiment described in detail in the previous section. It represents the other extreme case where no hydrous oxide growth occurs.

Experimen, 3 demonstrates that extending the upper potential limit of the cycle to $+1.50 \mathrm{~V}$ causes hydrous oxide growth to occur. Thus, the hydrous oxide is formed at potentials between +1.20 and $+1.50 \mathrm{~V}$. Above $+1.50 \mathrm{~V}$, the oxide begins to dissolve, and therefore higher potentials were not used in this work. Extension of the lower limit to $0 \mathrm{~V}$ (experiment 4 ) increased the rate of hydrous oxide growth slightly.

The most striking feature of the result of experiment 4 is that, despite the fact that the same amount of time was spent at 0 and $+1.50 \mathrm{~V}$ on each cycle as in experiment 1 , the hydrous oxide growth was only $25 \%$ of that observed in experiment 1 . In order to explain this, experiments 5 to 9 were undertaken.

Experiment 5 shows that scanning the potential between 0 and $+1.50 \mathrm{~V}$ rather than using a single potential step (experiment 1) causes a decrease in hydrous oxide growth rate. Experiments 6 and 7 show that the time spent at $+1.20 \mathrm{~V}$ (hydrous oxide in the $\operatorname{Ir}(\mathrm{IV})$ state) on either the positive or negative part of the cycle has no effect on hydrous oxide growth. Experiments 8 and 9 show that time spent at +0.40 $\mathrm{V}$ (hydrous oxide in the $\operatorname{Ir}(\mathrm{III})$ state) during the negative part of the cycle does cause a substantial decrease in hydrous oxide growth.

These results indicate that the hydrous oxide is lost in some way or becomes electrochemically inactive when the potential is held at $+0.4 \mathrm{~V}$, for example. However, when the potential of an electrode coated with hydrous oxide $\left(q_{\text {ox }, 1.3} \sim 0.8\right.$ $\mathrm{mC} /$ real $\mathrm{cm}^{2}$ ) was held at $+0.40 \mathrm{~V}$ for $16 \mathrm{~h}$, there was only a $3 \%$ decrease in $q_{\mathrm{ox}, 1.3}$. Thus, instability of the bulk hydrous oxide cannot account for the low growth rates in experiments $3,4,5,8$ and 9. A possible explanation will be presented in the "model" section of this paper.

\section{The first monolayer of hydrous oxide}

Ideally, an investigation of the first few monolayers of hydrous Ir oxide growth should commence with an electrode that is completely free of oxide. However, in practice it is difficult to prepare an electrode that is completely oxide-free. Electrode pretreatments usually involve oxidation of the electrode followed by reduction of the oxide, in the hope of yielding a clean oxide-free surface. Unfortunately, with Ir, this pretreatment leaves a small amount of hydrous oxide on the electrode and this cannot be reduced in $0.5 \mathrm{M} \mathrm{H}_{2} \mathrm{SO}_{4}$. The reversible wave at $E^{\circ \prime}=+0.980 \mathrm{~V}$ in Fig. 


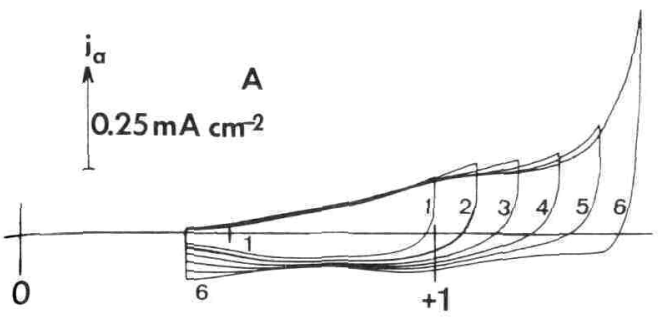

B

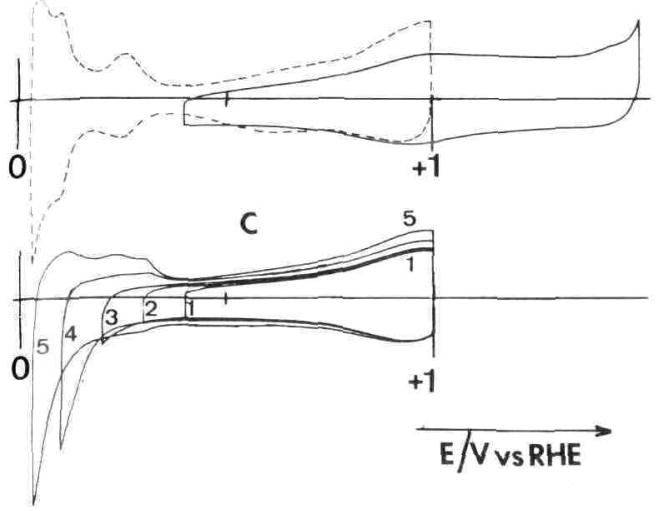

Fig. 4. A succession of voltammograms at $100 \mathrm{mV} / \mathrm{s}$ of $\mathrm{Ir}$ in $0.5 \mathrm{M} \mathrm{H}_{2} \mathrm{SO}_{4}$. See text for full explanation.

1A clearly shows that there is some residual hydrous oxide present. A possible explanation for this problem will be given in the "model" section.

However, it is possible to remove the residual hydrous oxide by cycling the potential of the electrode between +0.03 and $+1.20 \mathrm{~V}$ vs. RHE in $0.1 \mathrm{M} \mathrm{NaOH}$. The difference in $q_{\mathrm{ox}, 1.2}$ in $\mathrm{H}_{2} \mathrm{SO}_{4}$ before and after this treatment indicates that the residual hydrous oxide corresponds to a $q_{\mathrm{ox}, 1.2}$ of ca. $0.04 \mathrm{mC} / \mathrm{real} \mathrm{cm}^{2}$. This small amount of oxide was not considered to be a problem, so therefore the above treatment in $\mathrm{NaOH}$ was not generally used.

Figure $4 \mathrm{~A}$ shows a steady-state voltammogram between +0.40 and $+1.00 \mathrm{~V}$ of a

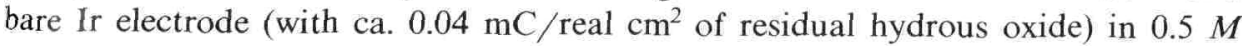
$\mathrm{H}_{2} \mathrm{SO}_{4}$ (curve 1). Also shown are subsequent cycles in which the upper potential limit was progressively increased to $+1.50 \mathrm{~V}$ (curves 2 to 6 ). The potential was then cycled between 0.40 and $1.50 \mathrm{~V}$ for $2 \mathrm{~h}$, after which the trace shown in Fig. 4B (- ) was obtained. Figure $4 \mathrm{C}$ shows the subsequent steady-state voltammogram between 0.40 and $1.00 \mathrm{~V}$ (curve 1), and also the voltammograms obtained as the lower potential limit was progressively decreased to $+0.03 \mathrm{~V}$ (curves 2 to 5). After 30 min of cycling between 0.03 and $1.00 \mathrm{~V}$, the voltammogram shown in Fig. 4B (- -) was obtained. 
The voltammograms in Fig. 4A correspond to exceeding the upper critical potential limit for oxide growth but not the lower critical limit. In the voltammograms in Fig. 4C, the potential was extended below the lower critical limit but not above the upper critical limit. As a hydrous oxide growth cycle must involve attaining potentials above the upper critical limit and also below the lower critical limit, only one hydrous oxide growth cycle is represented by Fig. 4. Thus, the series of voltammograms in Fig. 4 give a comprehensive picture of oxide growth during a single hydrous oxide producing cycle. Figure 4 will be used to summarise the major observations and assumptions on which our model for hydrous oxide growth is based.

The steady-state voltammogram obtained between the limits of 0.40 and $1.00 \mathrm{~V}$, shown in Fig. 4A (curve 1), represents double-layer charging and the reversible adsorption of $\mathrm{OH}$ onto the Ir metal [8]. At ca. $+1 \mathrm{~V}$, slow place exchange occurs [8,32], but virtually all the place-exchanged oxide is reduced back to metal during the negative part of the cycle. We assume here that place exchange occurs at Ir as it does at Pt [32,35], producing a thin, compact oxide layer.

As the upper potential limit is extended (Fig. 4A, curves 2 to 6), more place exchange occurs and a cathodic current due to the reduction of the compact inner oxide becomes apparent at potentials below $+0.6 \mathrm{~V}$. However, not all of this inner oxide is now reduced during the negative scan. Thus, the inner oxide accumulates so that on each positive scan, the oxidation currents become diminished and higher potentials are required to cause further growth of the compact oxide. This interpretation is based on oxide growth at $\mathrm{Pt}$, where the growth rate is proportional to the applied potential and inversely proportional to the oxide film thickness [35].

As the upper potential limit is extended beyond $+1.2 \mathrm{~V}$ (Fig. 4A, curves 4 to 6), a small broad reduction wave appears at ca. $1.0 \mathrm{~V}$. This indicates that some hydrous oxide has now been formed. Continuous scanning between 0.40 and $1.50 \mathrm{~V}$ does not lead to an increase in the size of the reversible hydrous oxide wave at ca. $1.0 \mathrm{~V}$, but the oxidation current above $1.0 \mathrm{~V}$ becomes suppressed as does the reduction current below $0.6 \mathrm{~V}$ (Fig. 4B, - ). Presumably, at this stage, enough inner oxide is present so that further growth of the inner oxide is very slow and its reduction is inhibited (cf. oxide growth at Pt [32]).

The steady-state voltammogram shown in Fig. 4B (- - ) thus corresponds to: (i) reversible $\operatorname{Ir}(\mathrm{IV} / \mathrm{III})$ electrochemistry of a small amount $\left(q_{\mathrm{ox}, 1.3} \sim 0.08 \mathrm{mC} / \mathrm{real}\right.$ $\mathrm{cm}^{2}$ ) of newly formed hydrous oxide and the residual hydrous oxide; (ii) double-layer charging of the inner oxide/solution interface; (iii) oxygen evolution at potentials close to $1.5 \mathrm{~V}$.

The sequence of voltammograms in Fig. 4C shows the kinetically irreversible reduction of the compact oxide. The initial suppression of $\mathrm{H}$-atom adsorption is clearly seen in curves 4 and 5 (cf. Fig. 4B, - - - ). The H-adsorption waves and the current due to the initial stages of oxide formation gradually reappear as the compact oxide is reduced. It is particularly significant that the compact oxide is reduced at a significant rate only at potentials below ca. $+0.3 \mathrm{~V}$, which is also the critical lower limit for sustained hydrous oxide growth. 
It is now possible to give a qualitative description of the processes which appear to occur during a hydrous-oxide growth cycle at Ir. During the positive scan (or after the positive pulse), a compact inner oxide is formed by a place-exchange mechanism and then some hydrous oxide is formed by oxidation and hydration of the outer portion of this inner oxide. On the negative scan (or after the negative pulse), the inner oxide is reduced back to the metal while the hydrous oxide is left on the surface of the metal. Continuous cycling builds up a thick, insoluble, hydrous oxide layer, which is presumably held at the electrode surface only by weak adsorption.

Quantity of hydrous oxide formed per cycle

During recording of the series of voltammograms of Fig. 4, the quantity of hydrous oxide (measured as $q_{\mathrm{ox}, 1.3}$ ) increased by only $0.08 \mathrm{mC} / \mathrm{real} \mathrm{cm}^{2}$. Similar figures have been obtained in other experiments. A repetition of the procedure used in Fig. 4 increased $q_{\text {ox } 1.3}$ by a further $0.08 \mathrm{mC} /$ real $\mathrm{cm}^{2}$. These results indicate that there is a limit to the amount of hydrous oxide that can be grown in a single cycle.

This is supported by the more accurate data in Table 2. We have found no way to grow more hydrous oxide per cycle than that grown with $100 \mathrm{~s}$ pulses between 0 and $1.50 \mathrm{~V}$. Under these conditions, the maximum growth per cycle was $\Delta q_{\mathrm{ox}, 1.3}=0.11$ $\mathrm{mC} /$ real $\mathrm{cm}^{2}$, with the corrected (see above) average of Table 2 being $0.10 \mathrm{mC} / \mathrm{real}$ $\mathrm{cm}^{2}$.

A simpler way to express these quantities is to convert them to a ratio of the number of Ir atoms entering the hydrous layer per cycle to the number of Ir atoms in the surface atomic layer of the metal. This is given by $\Delta q_{0 x, 1.3} / 0.218 x$, where $x$ is the fraction of $\operatorname{Ir}$ sites in the hydrous oxide that is oxidised to $\operatorname{Ir}(\mathrm{IV})$ at $+1.30 \mathrm{~V}$ and $0.218 \mathrm{mC} / \mathrm{real} \mathrm{cm}^{2}$ is the charge corresponding to 1 electron per $\mathrm{Ir}$ atom at the metal surface [30]. From chemical analysis of Ir oxide films, we have determined that $x \sim 1.2$ [37], and so the required ratio is ca. 0.4 .

We can conclude that only about half of the atoms in the surface atomic layer of the Ir metal can be converted into hydrous iridium oxide during any single oxidation procedure. Since it seems probable that it is an inner oxide and not the metal surface that is converted to the hydrous oxide, this result is quite reasonable. It suggests that only the outer monolayer of the inner oxide can be converted to the hydrous oxide.

A model

The outline of a model for oxide growth on Ir has been incorporated in to the discussions above. In this section, some details are added and the model is used to account for the experimental observations presented in earlier sections.

The first stage of oxide formation at $\mathrm{Ir}$ is the formation of an inner oxide by a place exchange mechanism as shown in Fig. 5A. We will assume this inner oxide to be $\mathrm{IrO}_{2}$ (Fig. 5B) [17]. We propose that the second stage, which occurs at potentials 


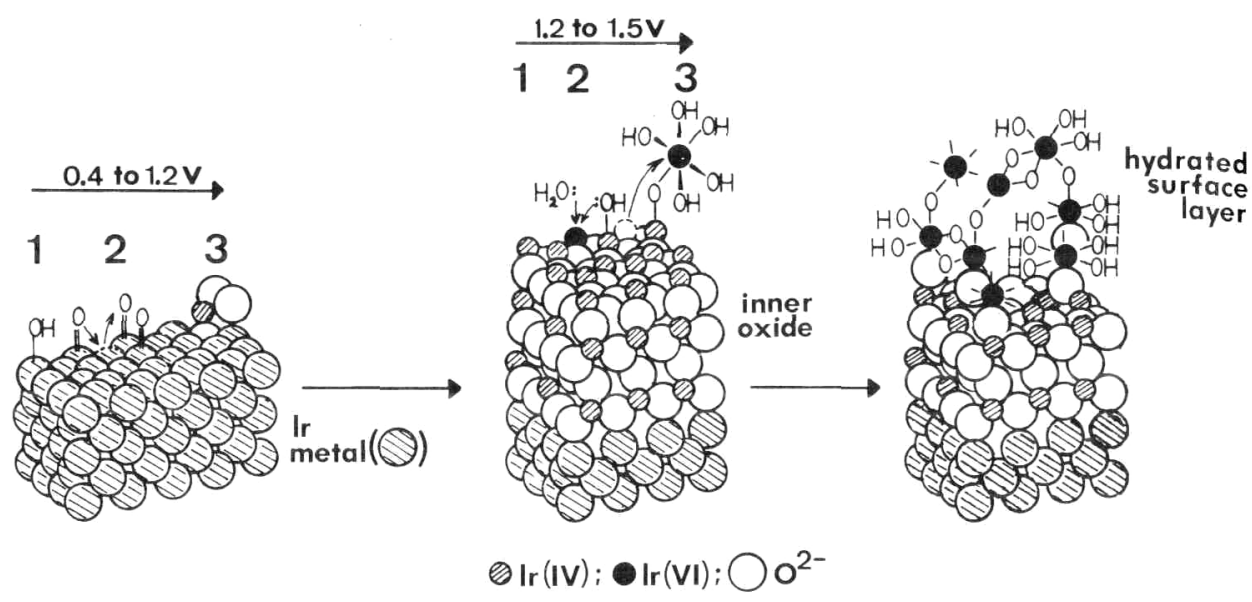

Aiafter 100 s at ov

Biafter $5 \mathrm{~min}$ at $1.2 \mathrm{~V}$

Ciafter 100 s at $1.5 \mathrm{~V}$

Fig. 5. Detailed diagram of the proposed mechanisms for oxide formation at Ir in $0.5 \mathrm{M} \mathrm{H}_{2} \mathrm{SO}_{4}$. The numbered structures on $\mathrm{A}$ and $\mathrm{B}$ indicate the mechanisms of the transitions to $\mathrm{B}$ and $\mathrm{C}$, respectively.

greater than $+1.2 \mathrm{~V}$, is the oxidation of the surface of this inner oxide in contact with the solution to a higher oxide (perhaps $\mathrm{IrO}_{3}$ ), which immediately becomes hydrated (Figs. 5B and 5C). The hydrated higher oxide monolayer catalyses the oxidation of water [9] and therefore its formation coincides with the onset of oxygen evolution at Ir. Because of the complication of concurrent oxygen evolution, the $\operatorname{Ir}(\mathrm{IV}) \leftrightarrow \operatorname{Ir}(\mathrm{VI})$ electrochemistry of neither the inner oxide nor the hydrous oxide can be identified clearly. However, it has been established $[3,11]$ that the hydrous layer is reduced to $\operatorname{Ir}(\mathrm{IV})$ at potentials below ca. $+1.4 \mathrm{~V}$, and to $\operatorname{Ir}(\mathrm{III})$ at $E^{\circ} \sim 1.0$ $V$. The hydrated surface of the inner oxide must be different from the bulk hydrous oxide, formed in previous cycles, because it is bonded to the inner $\mathrm{IrO}_{2}$ layer (see Figs. 5B and 5C).

If the potential is held at $+1.5 \mathrm{~V}$, a stable surface structure is obtained (Fig. 5C). Further oxidation of the inner $\mathrm{IrO}_{2}$ layer is inhibited by the presence of the hydrated surface layer and therefore no more than a monolayer of hydrated oxide is formed. This inhibition is probably caused by the fact that there is little access of the electrolyte to the second layer of the $\mathrm{IrO}_{2}$. Hence the applied potential difference is dropped across the hydrated surface layer/solution interface rather than across the inner oxide/hydrated surface layer interface. A similar situation arises with bulk $\mathrm{RuO}_{2}$ where only the outer monolayer is electroactive [38,39].

When the oxidised Ir electrode is reduced, the inner $\operatorname{IrO}_{2}$ layer is reduced to $\mathrm{Ir}$ metal but the now hydrated surface layer cannot be reduced to the metal at the potentials (e.g. $0 \mathrm{~V}$ ) used. Therefore a monolayer of hydrous $\operatorname{Ir}(\mathrm{III})$ oxide is left on the electrode.

Following reduction at $0 \mathrm{~V}$ for a sufficient length of time (a few seconds), if the electrode is reoxidised, the sequence described above is repeated and a further 
monolayer of hydrous oxide is formed. Thus, the quantity of hydrous oxide left on the electrode surface following reduction builds up with each cycle.

Once the inner oxide has been reduced, the hydrated oxide is no longer bound to the electrode except by weak electrostatic forces and Van der Waals forces. Therefore, the normal electrochemistry (i.e. H adsorption and oxide formation) of the Ir metal is hardly affected by its presence. However, if the inner oxide layer is not fully reduced, then the $\mathrm{H}$-adsorption process is inhibited (Fig. 4C). When hydrous oxide is grown with a lower potential limit which is insufficiently negative to permit the complete reduction of the inner oxide in the allowed time, the inner oxide builds up. The result is a decrease in $q_{\mathrm{H}}$ and a loss of hydrous oxide growth efficiency (Fig. 2). The latter occurs because, in any cycle, the only new hydrous oxide that enters the hydrous oxide phase is that part of the surface of the inner oxide that has been freed by the reduction of the underlying inner oxide. The greatest quantity of hydrous oxide that can be formed per cycle is obviously one monolayer. This is in agreement with the observed limit of $1 / 2$ of the Ir atoms in the metal surface layer, which is approximately equivalent to all of the Ir atoms in a single layer of $\mathrm{IrO}_{2}$ (see Fig. 5B).

It is not known how thick the inner oxide layer becomes, but the charge densities in Table 1 indicate that ca. 1.5 monolayers of Ir metal are oxidised to $\operatorname{Ir}(\mathrm{IV})$ after 5 $\min$ at $+1.20 \mathrm{~V}$. This corresponds to the formation of ca. 3 layers of $\mathrm{IrO}_{2}$. Charges measured during reduction of oxide films formed at $+1.50 \mathrm{~V}$ indicate that the inner $\mathrm{IrO}_{2}$ layer does not become significantly thicker than this. Thus Fig. $5 \mathrm{C}$ is probably a fair representation of the Ir surface following oxidation at $+1.5 \mathrm{~V}$. This structure is attained after only a few seconds and does not change significantly during prolonged oxidation.

The above mechanism explains why some residual hydrous oxide is left on the electrode surface after the pretreatment procedure. The electrode is oxidised during pretreatment and although most of the hydrous oxide is dissolved, there must still be an inner oxide layer present, having a hydrated surface layer. Reduction therefore leaves this hydrated material as the residual hydrous oxide.

The final point to be addressed is the loss of hydrous oxide growth efficiency which occurs when the potential is scanned from the upper limit to the lower limit or when the potential is held at 0.2 or $0.4 \mathrm{~V}$ during the negative part of the cycle (Table 2). At potentials between 0.2 and $0.7 \mathrm{~V}$, the hydrated surface layer of the inner oxide is reduced to hydrated $\operatorname{Ir}(\mathrm{III})$ oxide while the rest of the inner oxide is only very slowly reduced to the metal. While the electrode potential is in this range, the hydrated surface layer slowly ceases to be electroactive at $+1.0 \mathrm{~V}$ and this leads to the decrease in hydrous oxide growth per cycle. A possible explanation for this is that the hydrated surface layer becomes dehydrated and is then reduced to Ir metal at $0 \mathrm{~V}$. Possible products of the dehydration are $\mathrm{Ir}_{2} \mathrm{O}_{3}, \mathrm{IrO}_{2}$ (by simultaneous oxidation by the electrode) or Ir metal and $\mathrm{IrO}_{2}$ (by disproportionation).

The model discussed above is summarised in Fig. 6. Once a stable tri-layer of inner oxide $\left(\mathrm{IrO}_{2}\right)$, hydrated surface layer (HSL) and bulk hydrous oxide (BHO) has been formed at $+1.5 \mathrm{~V}$, the potential must be taken to approximately $0 \mathrm{~V}$ in order 


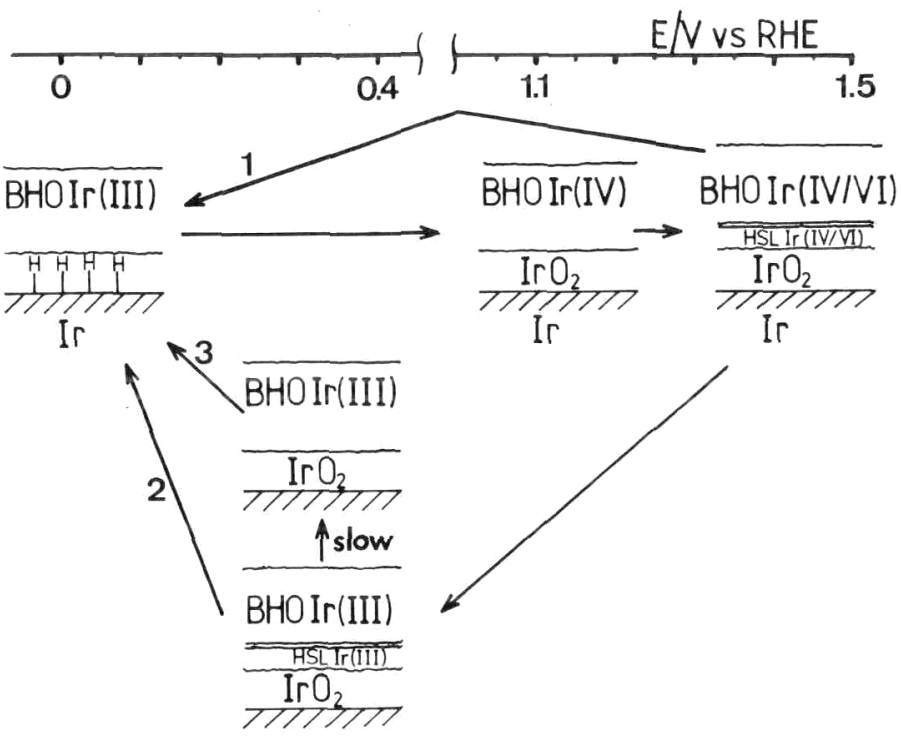

Fig. 6. Schematic diagram of the overall mechanism of hydrous oxide growth under potential cycling conditions. $\mathrm{BHO}=$ bulk hydrous oxide; $\mathrm{HSL}=$ hydrated surface layer .

to reactivate the electrode by reduction of the inner oxide. At this point the hydrated surface layer becomes part of the bulk oxide layer. Hydrous oxide growth is most efficient if the potential is stepped from 1.5 to $0 \mathrm{~V}$ (route 1 in Fig. 6). If the hydrated surface layer is allowed to remain in the $\operatorname{Ir}(\mathrm{III})$ state for any length of time (routes 2 and 3 ; e.g. if the potential is scanned from 1.5 to $0 \mathrm{~V}$ ), then a slow decomposition of the hydrated surface layer leads to an inefficiency in the hydrous oxide growth.

\section{CONCLUSIONS}

The main new feature of the model discussed above and represented in Figs. 5 and 6 , is the postulation of a hydrated surface layer on a compact inner oxide. This hydrated monolayer has similar electrochemical properties to the bulk hydrous oxide but differs from it in that it is strongly bound to the inner oxide. The hydrated monolayer becomes part of the bulk hydrous oxide only when the inner oxide is reduced to Ir metal. This explains the need to cycle the electrode potential below a critical lower limit in order to obtain an accumulation of the hydrous oxide.

An important consequence of the fact that the hydrated monolayer is chemically different from the bulk hydrous oxide is that it has a different chemical stability. Thus, when it is in the Ir(III) state it is unstable whereas the bulk hydrous oxide is stable in the $\operatorname{Ir}(\mathrm{III})$ form. Because of this, hydrous oxide accumulation is slower when the potential is scanned between the upper and lower limits of the growth cycle than when it is stepped. This is true even when the time spent at the two limits 
is the same in both cases. Therefore, for most rapid hydrous oxide growth, potential pulsing should be used.

The model proposed here may also be applicable to oxide growth at other metals such as $\mathrm{Pt}$ and $\mathrm{Au}$. At these metals, however, the hydrous oxide can be grown at constant potential. The difference may lie in the higher potentials that can be used with $\mathrm{Pt}$ and $\mathrm{Au}$, without significant dissolution occurring. At sufficiently high potential, the electric field in the region of the hydrated surface layer/inner oxide interface will cause oxidation and hence hydration of further layers of the inner oxide. However, more rapid growth of the hydrous oxide can be obtained if the inner oxide is repeatedly reduced and reformed by cycling the electrode potential. If the above model is applicable, the explanation for this is that, each time the inner oxide is reformed, a monolayer of hydrated oxide is formed very rapidly whereas formation of further hydrous oxide at constant potential is very slow in comparison.

\section{ACKNOWLEDGEMENT}

This work was supported by Allied Canada Incorporated and the Natural Sciences and Engineering Research Council of Canada, to whom we are grateful.

\section{REFERENCES}

1 L.D. Burke in S. Trasatti (Ed.), Electrodes of Conductive Metallic Oxides, Part A, Elsevier, Amsterdam, 1981, p. 141

2 S. Gottesfeld and J.D.E. McIntyre, J. Electrochem. Soc., 126 (1979) 742.

3 J.D.E. McIntyre, W.F. Peck, Jr. and S. Nakahara, J. Electrochem. Soc., 127 (1980) 1264.

4 G. Beni, C.E. Rice and J.L. Shay, J. Electrochem. Soc., 127 (1980) 1342.

5 S.H. Glarum and J.H. Marshall, J. Electrochem. Soc., 127 (1980) 1467.

6 L.D. Burke and D.P. Whelan, J. Electroanal. Chem., 124 (1981) 333.

7 J.L. Ord, J. Electrochem. Soc., 129 (1982) 335.

8 J. Mozota and B.E. Conway, Electrochim. Acta, 28 (1983) 1, 9.

9 R. Kötz, H. Neff and S. Stucki, J. Electrochem. Soc., 131 (1984) 72.

10 J. Augustynski, M. Koudelka, J. Sanchez and B.E. Conway, J. Electroanal. Chem., 160 (1984) 233.

11 L.D. Burke and D.P. Whelan, J. Electroanal. Chem., 162 (1984) 121.

12 L.D. Burke, J.K. Mulcahy and D.P. Whelan, J. Electroanal. Chem., 163 (1984) 117.

13 V. Birss, R. Myers, H. Angerstein-Kozlowska and B.E. Conway, J. Electrochem. Soc., 131 (1984) 1502 .

14 L.D. Burke and R.A. Scannell, J. Electroanal. Chem., 175 (1984) 119.

15 W. Bold and M. Breiter, Electrochim. Acta, 5 (1961) 169.

16 M.W. Breiter, Z. Phys. Chem., 52 (1967) 73.

17 J.P. Hoare, J. Electroanal. Chem., 18 (1968) 251.

18 P. Stonehart, H. Angerstein-Kozlowska and B.E. Conway, Proc. R. Soc. Lond., Ser. A, 310 (1969) 541

19 A. Capon and R. Parsons, J. Electroanal. Chem., 39 (1972) 275.

20 J.M. Otten and W. Visscher, J. Electroanal. Chem., 55 (1974) 1, 13.

21 D.A.J. Rand and R. Woods, J. Electroanal. Chem., 55 (1974) 375.

22 D.N. Buckley and L.D. Burke, J. Chem. Soc. Faraday Trans. 1, 71 (1975) 1447.

23 D.N.Buckley, L.D. Burke and J.K. Mulcahy, J. Chem. Soc. Faraday Trans. 1, 72 (1976) 1896.

24 D. Michell, D.A.J. Rand and R. Woods, J. Electroanal. Chem., 84 (1977) 117. 
25 S. Gottesfeld and S. Srinivasan, J. Electroanal. Chem., 86 (1978) 89.

26 L.D. Burke and M. McRann, J. Electroanal. Chem., 125 (1981) 387.

27 L.D. Burke and G.P. Hopkins, J. Appl. Electrochem., 14 (1984) 679.

28 L.D. Burke and M.B.C. Roche, J. Electroanal. Chem., 137 (1982) 175.

29 L.D. Burke and M.B.C. Roche, J. Electroanal. Chem., 164 (1984) 315.

30 R. Woods, J. Electroanal. Chem., 49 (1974) 217.

31 J. Mozota and B.E. Conway, J. Electrochem. Soc., 128 (1981) 2142.

32 H. Angerstein-Kozlowska, B.E. Conway and W.B.A. Sharp, J. Electroanal. Chem., 43 (1973) 9.

33 B.E. Conway and S. Gottesfeld, J. Chem. Soc. Faraday Trans. 1, 69 (1973) 1090.

34 K.J. Vetter and J.W. Schultze, J. Electroanal. Chem., 34 (1972) 131, 141.

35 A. Damjanovic, A.T. Ward, B. Ulrick and M. O'Jea, J. Electrochem. Soc., 122 (1975) 471.

36 L.B. Harris and A. Damjanovic, J. Electrochem. Soc., 122 (1975) 593.

37 P.G. Pickup and V.I. Birss, J. Electroanal. Chem., submitted.

38 L.D. Burke and O.J. Murphy, J. Electroanal. Chem., 96 (1979) 19.

39 L.D. Burke and J.F. Healy, J. Electroanal. Chem., 124 (1981) 327. 